\title{
Bjomédica
}

Articulo Original

\section{La enfermedad de Chagas: retos del tratamiento}

Eugenia del S. Guzmán Marín, Karla Y. Acosta-Viana, Matilde Jiménez-Coello Laboratorio de Biología Celular. Centro de Investigaciones Regionales, "Dr. Hideyo Noguchi" Universidad Autónoma de Yucatán.

\section{Autor para correspondencia}

Nombre: Eugenia del S. Guzmán Marín

Institución: "Dr. Hideyo Noguchi" Universidad Autónoma de Yucatán

Departamento: Laboratorio de Biología Celular.

E-mail: revistabiomedica@ correo.uady.mx

Copyright () 2016 por autores (s) y Revista Biomédica.

Este trabajo esta licenciado bajo las atribuciones de la Creative Commons (CC BY).

http://creativecommons.org/licenses/by/4.0/

(C) (i) Open Access 


\section{Guzmán-Marín et al}

La enfermedad de Chagas o tripanosomiasis americana es una parasitosis ocasionada por el protozoario hemoflagelado Trypanosoma cruzi (T. cruzi), el cual es transmitido al hombre y a otros mamíferos principalmente a través de insectos hematófagos de la subfamilia Triatominae. Otras formas de transmisión son la sanguínea, a través de trasplante de órganos, la vía congénita, por accidentes de laboratorio y la vía oral. En cuanto a la vía congénita se estima que, en Latinoamérica, existen unos 2 millones de mujeres en edad fértil, con capacidad para transmitir el parásito al feto. Así mismo, se ha reportado que se infectan, al menos, 15,000 neonatos cada año en Latinoamérica y 2,000, en Norteamérica (1).

Esta enfermedad, se encuentra ampliamente distribuida en áreas endémicas de América Latina, sin embargo, en las últimas décadas, la Organización Mundial de la Salud (OMS) ha reportado un aumento en el número de casos en países europeos, Canadá, Estados Unidos de América y otros algunos países del Pacífico Occidental, donde actualmente ya se considera un problema de salud pública, debido a que representa una carga económica por su prolongada cronicidad; éste fenómeno es atribuido a la gran movilidad de las poblaciones endémicas, hacia el resto del mundo. En cuanto al desarrollo clínico, la enfermedad es considerada muy compleja, dado que va de una forma asintomática hacia la sintomática, iniciando con una fase aguda que puede prolongarse hasta dos meses posterior a la adquisición de la infección, cursando asintomática en la mayoría de los casos. Posteriormente, una gran proporción de pacientes entra a la fase indeterminada o crónica asintomática, que puede transcurrir entre 5 y 30 años, con niveles de parasitemia prácticamente indetectables. En la fase crónica, los parásitos se internan en las células de órganos como corazón y sistema digestivo y, años después, pueden causar destrucción del músculo cardiaco, causando insuficiencia cardiaca o muerte súbita (2).

Es importante señalar que, en general, los programas de control orientan las estrategias hacia el vector, dejando al paciente infectado en segundo plano. De manera que, a más de 100 años de su descubrimiento por el Dr. Carlos Ribeiro Justiniano Chagas, aún no se cuenta con el tratamiento ideal. Desde 1960 se cuenta con dos medicamentos, benznidazol (bz) y nifurtimox (nf), ambos utilizados principalmente para la fase aguda de la enfermedad, ya que son efectivos en las formas extracelulares de $T$. cruzi observadas en la fase aguda, sin embargo, su efecto es menor en las formas intracelulares del parásito que se encuentran durante la fases indeterminada y crónica. Así mismo, ambas drogas tienen efectos colaterales adversos y, dado que se requieren largos periodos de tratamiento con una eficacia variable es, en ocasiones, controvertida su administración. Actualmente, de acuerdo a diversos estudios científicos, la OMS reporta que bz y nf solo son activas en las fases aguda y crónica 
temprana (pocos años de duración) de la enfermedad, de igual manera, hacen notar que la evidencia científica sobre la eficacia de los fármacos ha llevado a incluir en el tratamiento a adultos en fase crónica que no presenten una cardiomiopatía avanzada (3-5).

Se encuentra bien documentado que $60 \%$ de los tratamientos resultan eficaces durante la fase aguda de la enfermedad y se describe que estas terapias son eficaces en el tratamiento de niños que adquieren congénitamente la infección. Sin embargo, existe la necesidad de desarrollar nuevas opciones profilácticas y terapéuticas para la prevención y el control de la enfermedad.

Existen estudios sobre fármacos alternativos a bz y nf, de posible utilidad en la enfermedad crónica, como el Posaconazol y Rabuconazol, ambos en fase de prueba y aunque se han probado más de 100 productos experimentales con diferentes estructuras químicas, únicamente algunos de ellos han completado los estudios de la fase preclínica con éxito relativo, debido a que muchos de ellos han demostrado inducir resistencia en el parásito. También, se ha probado un gran número de derivados de productos naturales, muchos de ellos utilizados en prácticas de la medicina tradicional, que podrían considerarse como nuevas opciones de tratamiento (3).

El agente tripanocida ideal debe ser selectivo y actuar sobre las formas intra y extracelulares; de forma rápida, para impedir la evolución hacia la fase crónica; su farmacodinamia debe alcanzar niveles efectivos tripanocidas de concentración del fármaco en el plasma sanguíneo, en fluidos biológicos y en tejidos, no debe inducir resistencia del parásito al medicamento y debe, además, ser de bajo costo y fácil disponibilidad (4).

El criterio de cura es la persistencia de resultados serológicos negativos, sin embargo, toma mucho tiempo la reducción de los títulos de anticuerpos específicos utilizando serología convencional posterior al tratamiento de pacientes crónicos y las pruebas utilizadas para la detección del parásito en esta fase, muchas veces, carecen de sensibilidad. En los últimos años, se utiliza la reacción en cadena de la polimerasa (PCR) como herramienta para detectar parásitos en sangre de estos pacientes, sin embargo, los resultados negativos no garantizan que los pacientes se hayan curado, sin embargo, a falta de biomarcadores eficaces, la PCR es, al día de hoy, la estrategia utilizada.

Dado que, actualmente el riesgo de infección por T. cruzi se ha propagado a otros continentes, además de América Latina, a pesar de las medidas de control vectorial y que el tratamiento se considera insatisfactorio, pues aún no se cuenta con fármacos idóneos y efectivos contra la fase crónica, es verdaderamente un reto y se hace necesario contar con nuevas alternativas de tratamiento específico e inocuo para ésta fase de la enfermedad. Por lo tanto, se hace necesario sumar esfuerzos propiciando 


\section{Guzmán-Marín et al}

iniciativas multidisciplinarias y multinacionales para avanzar y afrontar los retos futuros relacionados con el tratamiento de la enfermedad de Chagas.

\section{Referencias}

1. Jasso Gutiérrez L. Infecciones congénitas de baja frecuencia en los neonatos. Algunos aspectos relevantes. Bol Med Hosp Infant Mex. 2011;68(1).

2. Fumadó V, Juncosa T, Posada P, Fisa R, Gállego M, Gascón J. Chagas pediátrico en zona no endémica. Enferm Infecc Microbiol Clin. 2014;32:293-6.

3. OMS. La enfermedad de Chagas (tripanosomiasis americana). Nota No. 340, marzo 2016.

4. Rodrigues Coura J, de Castro SL. A critical review on Chagas disease chemotherapy. Mem Inst Oswaldo Cruz. 2002; 97:3-24.

5. Canales Martínez M, Hernández Delgado T, Caballero Nieto J, Alfonso Romo, de Vivar Romo A, Durán Díaz A, Lira Saade R. Análisis cuantitativo del conocimiento tradicional de las plantas medicinales en San Rafael, Coxcatlán, valle de Tehuacán-Cuicatlán, Puebla. Acta Botánica Mexicana, 2006. 75:21-43. Americana. Boletín Epidemiológico. SINAVE, SS, México. 16-22 de noviembre del 2014;31-Semana 47. 